\title{
Parametric Study of Energy Dissipating Steel Plate Fuses
}

\author{
Ahmad Siar Mahmood Shah ${ }^{1}$, Saber Moradi ${ }^{2}$ \\ ${ }^{1}$ Graduate Research Assistant, Ryerson University \\ 350 Victoria St, Toronto, M5B 2K3, Canada. \\ ahmad.mahmood@ryerson.ca; s.moradi@ryerson.ca \\ ${ }^{2}$ Assistant Professor, Ryerson University \\ 350 Victoria St, Toronto, M5B 2K3, Canada.
}

\begin{abstract}
Steel plate devices are broadly used in earthquake-resistant structures to provide energy dissipation. Understanding the cyclic response of these steel plate fuses requires comprehensive investigation of different fuse link design parameters. This goal can be achieved using finite element analysis. This paper presents the finite element modeling and sensitivity study of steel plate fuse links. Threedimensional finite element models are first developed and validated against past experimental tests. While validating the finite element models, several important components, including element type, material and meshing properties, boundary conditions, loading profile, and analysis method are discussed. The design of experiment (DOE) is then used to generate factor combinations for the parametric study. Seven potentially influential design factors related to the material or geometry of steel plate fuses are considered as input factors. Next, the cyclic response of fuses is assessed in terms of initial stiffness, yield strength, ultimate stiffness, effective damping, maximum load capacity, and ductility. The percentage contribution of significant design factors on each cyclic response variable is obtained.
\end{abstract}

Keywords: Finite element simulation, Steel plate fuse, Energy dissipating device, Sensitivity analysis, Statistical design of experiment.

\section{Introduction}

Earthquakes can severely damage structures. The traditional seismic design approach has been based on providing adequate ductility to withstand the imposed loads. While life safety is met, damage to structures is probable under major earthquakes. To mitigate damage, researchers propose using damage avoidance design mechanisms that rely on energydissipating devices. The presence of energy dissipation in structures has been studied by several researchers [1], [2]. It has been recognized that, as a vibration control method, energy dissipating system leads the input energy from the earthquake to special devices (steel plates), thereby reducing energy dissipating demand on primary structural components and minimizing possible structural damage [3].

The inelastic deformation of energy dissipating devices is an essential mechanism for input earthquake energy dissipation. In addition, a steel plate device or fuse element that is accessible and easily replaceable is also a popular and inexpensive choice for energy dissipation because of its relatively sufficient ductility and effectiveness in the post-yield region. The damping, ductility, and reusability of steel have made it ideal for wide applications in energy dissipating devices (e.g., [4]). Particularly, the developments of self-centering rocking frames rely on the energy dissipation of steel shear plate fuses (e.g., [5], [6]).

The idea of utilizing steel plate fuses in structures to absorb a large portion of the seismic energy has first begun with the conceptual and experimental work by Kelly et al. [7]. Then several studies, investigating various types of energy dissipating steel plate elements have been proposed (e.g., [8]). Past theoretical and experimental research shows different applications of steel plate fuses [9], [10].

Numerous studies have examined the energy dissipation and hysteretic response of steel shear plates and dampers. Among others, Ma et al. [11] has experimentally tested butterfly-shaped fuses (with diamond-shaped openings) and slit fuses (with rectangular openings). By making openings or cuttings in the plate, the plate's buckling and ductile behavior is enhanced because a flexural mode may govern, as opposed to a single plate's prevailing shear mode response. Further, an individual shear link is more compact than a solid plate. Chan and Albermani [12] developed and tested a new steel slit damper (SSD). They reported that the device exhibited stable hysteresis with excellent energy dissipation and ductility. 
Ghabraie et al. [13] found that diamond-shaped cuts were optimal based on a topology optimization of SSDs in terms of energy dissipation. Deng et al. [14] studied the shape optimization of steel shear panel dampers by minimizing the maximum equivalent plastic strain in simulated models.

In this paper, the finite element simulation of steel plate fuses is presented along with a sensitivity study. Threedimensional finite element (FE) models are developed and validated for steel plate fuses in ANSYS Mechanical APDL [15]. For a satisfactory level of accuracy in the validation of the FE simulation several components including the element type, material and meshing properties, boundary conditions, loading history, and analyses have been described. Following that, the design of experiment (DOE) method is used to generate factor combinations providing the database for evaluating the influence of different design factors related to geometry (i.e., length, $L$; end-width, $b$; mid-width, $a$; thickness, $t$; and the band zone length, $c$ ) and material (i.e., modulus of elasticity, $E$; and steel yield strength, $F_{y}$ ) of steel plate fuses on the cyclic response of shear links. Next, the contribution of significant factors on the cyclic response is evaluated.

\section{Finite Element (FE) Modeling}

Previously the FE modeling of slit and butterfly-shaped steel plate fuses has been presented in several studies (e.g., [16], [17]). In this context, the procedure for numerical analysis of slit and butterfly-shaped fuses under cyclic loading is discussed. The assumptions and modeling approaches are briefly described. Furthermore, the accuracy of the computer modeling is verified under both cyclic and monotonic loading conditions based on experimentally tested specimens in Lee et al. [18] and Farzampour and Eatherton [19]. The fuse response and failure mode are studied and compared with the experimental test results.

\subsection{Reference Slit and Butterfly-shaped Steel Plate Fuses}

In the present study, two specimens from the non-uniform steel strip dampers tested by Lee et al. [18] are chosen for the calibration and verification of FE modeling results under cyclic loading. Further, three different single-link specimens from the numerical study by Farzampour and Eatherton [19] are modeled to confirm the accuracy of the FE analysis results, which is based on the response of a single link of the fuse. These specimens exhibit three different limit states including flexural yielding, shear yielding, and lateral torsional buckling.

The experimentally tested specimens by Lee et al. [18] include a conventional prismatic strip damper (PSD, which has slit or straight openings) and a dumbbell-shaped damper (DSD also known as butterfly-shaped fuses), as shown in Fig. 1 and 2, respectively. Table 1 summarizes the dimensional details of each specimen used for verification purposes. In Table 1, the letter $r$ denotes the radius of the round cut edges at the end of the link and $n$ describes the number of links in the specimen.

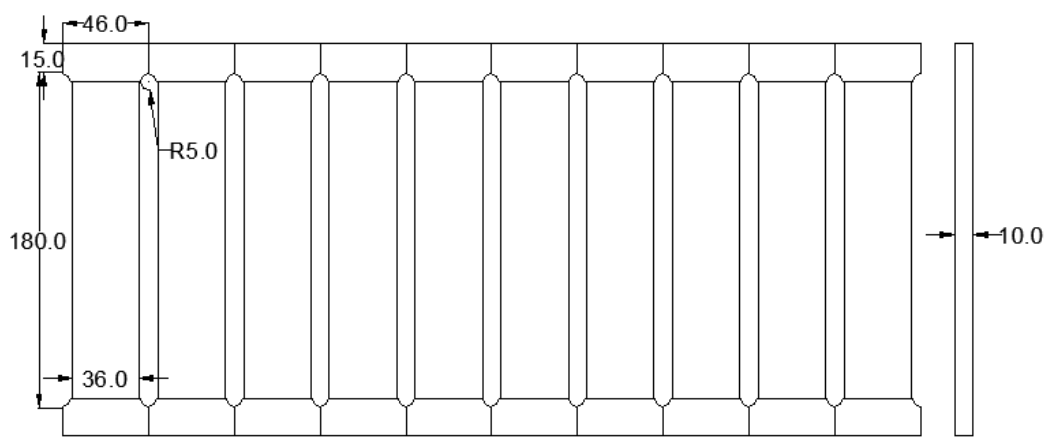

Fig. 1: Details of PSD-5 specimen used for the validation study (all dimensions are in $\mathrm{mm}$ ) [18]. 


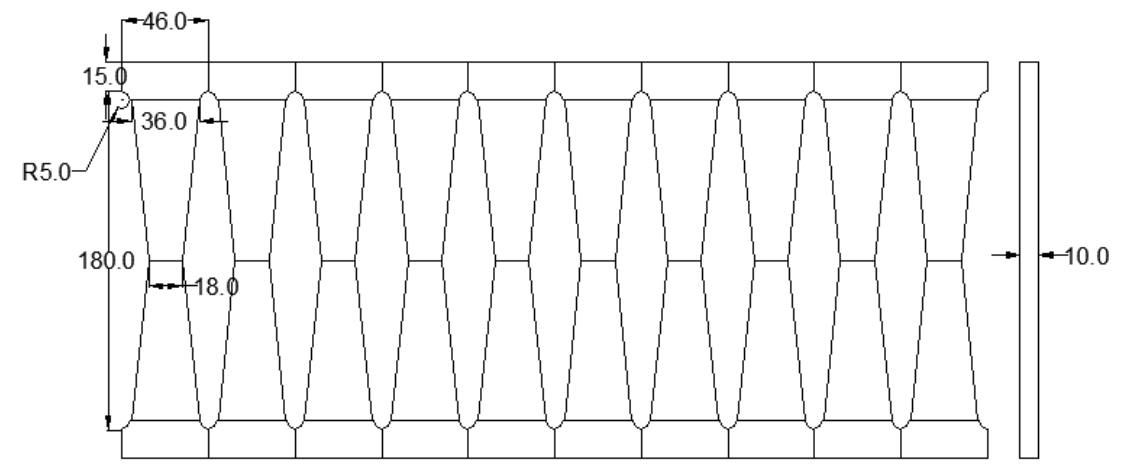

Fig. 2: Details of DSD-5 specimen used for the validation study (all dimensions are in $\mathrm{mm}$ ) [18].

Table 1: Dimensional details of the specimens used for the validation study [18], [19].

\begin{tabular}{|c|c|c|c|c|c|c|}
\hline Specimen/limit state & $L(\mathrm{~mm})$ & $a(\mathrm{~mm})$ & $b(\mathrm{~mm})$ & $t(\mathrm{~mm})$ & $r(\mathrm{~mm})$ & $n$ \\
\hline PSD-5 & 180 & 36 & 36 & 10 & 5 & 10 \\
\hline DSD-5 & 180 & 18 & 36 & 10 & 5 & 10 \\
\hline Shear yielding & 1000 & 100 & 500 & 20 & 5 & 1 \\
\hline Flexural yielding & 1000 & 100 & 300 & 20 & 5 & 1 \\
\hline Lateral torsional buckling & 500 & 100 & 100 & 16.67 & 5 & 1 \\
\hline
\end{tabular}

\subsection{Development of FE Models}

To evaluate the cyclic response of highly nonlinear steel plate fuses, 3D FE models are developed and analyzed in the finite element software, ANSYS Mechanical APDL [15]. Afterward, to achieve a satisfactory level of accuracy in the FE simulations, several trial models are investigated. To reduce the computational cost (i.e. running time duration and demand for resources), only one link of the fuse plate is modeled and the test setup components are not modeled. Appropriate boundary conditions are directly applied to the fuse model to simulate the proper behavior of the fuse. Fig. 3 shows the developed model for PSD-5 specimen.

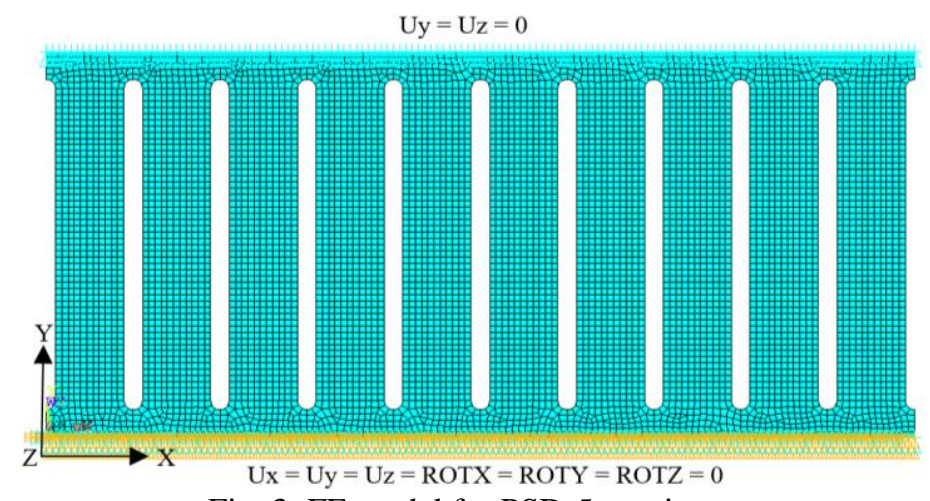

Fig. 3: FE model for PSD-5 specimen.

\subsection{Element Type}

Several initial runs using different element types have been explored. First the analysis results of solid and shell elements are compared with the experimentally tested specimens. It is observed that shell elements can better capture the behavior of 
the experimentally tested specimens in terms of load-deformation response, stress distribution and the out-of-plane deformation.

Among shell elements, SHELL281 and SHELL181 element types are thoroughly studied. Shell elements are for analyzing thin to moderately thick shell structures. These elements are well suited for linear larger rotation, and/or strain nonlinear applications. Change in the thickness is accounted for in linear and nonlinear analyses. Both element have shown promising load-deformation responses when compared to the experimentally tested specimens. However, SHELL281, having eight nodes with six degrees of freedom at each node: 3 translational (Ux, Uy, Uz) and 3 rotational (ROTX, ROTY, ROTZ), takes more computation time when compared to 4-node SHELL181 elements. Therefore, SHELL181 elements with reduced integration are used for the models in this study.

\subsection{Material Properties}

Selection of the right material model is the most challenging part of the validation in the FE simulation. From the ANSYS material library, several types of material models are compared to check the behavior of the model. The loaddeformation responses are then compared with the experimental results to find the best matching material model for the numerical simulations. Among the material models, different models including bilinear elastic perfectly plastic, multilinear kinematic hardening model, the NLISO model (Chaboche model combined with nonlinear isotropic hardening) and combined isotropic and kinematic hardening model have been used and compared. As a result of these comparisons, NLISO model (Chaboche model combined with non-linear isotropic hardening) is used as the material model in this study. Values of $200 \mathrm{GPa}$ and $295 \mathrm{MPa}$ are used as the elastic modulus of elasticity and yield stress of steel, respectively, based on the coupon tests reported in [18].

The NLISO material model is especially suitable for large-deformation analyses. Three different constant values, including $R_{0}, R_{\infty}$, and $b_{0}$ should be specified when using this material model. These values characterize the isotropic hardening behavior of the material. $R_{0}$ is the initial isotropic hardening modulus while $R_{\infty}$ is the asymptotic hardening value. $b_{0}$ controls the decrease of hardening in the function of equivalent plastic strain. For the verified models, values of 16,30 and 50 are used for $R_{0}, R_{\infty}$ and $b_{0}$, respectively [20].

\subsection{Boundary Conditions}

In the experimental test setup by Lee et al. [18], the loading has been applied by displacement control through the inner displacement transducer using a quasi-static $500 \mathrm{kN}$ actuator. Considering the experimental setup, in the FE model, the bottom of the plate at the bolt line is fixed against out-of-plane as well as vertical translation. A roller reaction at the top edge of the specimen is assumed where it can only move in the direction of loading and is constrained against outof-plane and vertical translation. The load in the FE model is applied at the top edge of the plate. It is also worth mentioning that the band zone areas at the top and the bottom of the plate are modeled to better capture the stiffness of the model. Fig. 3 shows the FE model with the defined boundary conditions.

\subsection{Meshing Properties}

The mesh density of the FE model is controlled using mesh control features in ANSYS Mechanical APDL [15]. Line and element sizes are assigned, and an automated free mesh is generated for the entire model. Free meshing provides the most desirable regular meshing in irregular shapes. Creating a fine enough and regular mesh is vital for capturing the proper cyclic response and overcoming possible convergence problems. A mesh sensitivity study is carried out and based on the results, an element size of $3.5 \mathrm{~mm}$ is used for the fuse model. It is confirmed that imperfection is not significantly influencing the response of steel fuse models. Thus, no imperfection is introduced in the models.

\subsection{Loading Profile}

To find the accumulated damage in the models due to the hysteretic loading, a displacement-controlled cyclic loading profile with incremental amplitudes similar to the experimental setup by Lee et al. [18], is applied. The loading 
protocol consists of symmetrical cyclic drift ratio with incrementally increasing amplitudes. The incremental variation for the amplitudes of first 12 steps of loading is increased with a ratio of 1.40 .

Cyclic Loading Profile

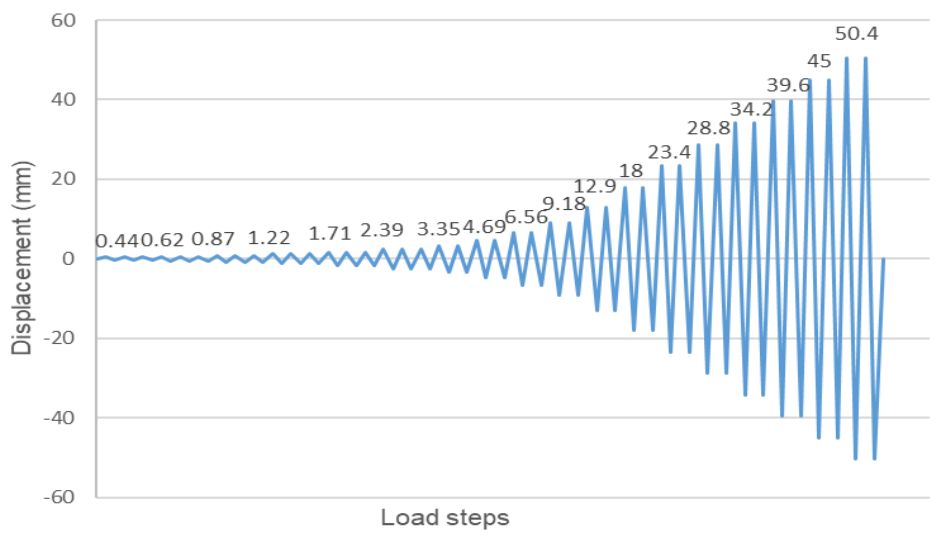

Fig. 4: Cyclic loading history.

\subsection{Analysis}

Nonlinear static analyses with full Newton-Raphson solution scheme considering the geometric and material nonlinearities are performed in ANSYS Mechanical APDL [15]. In order to overcome convergence difficulties, the minimum number of sub-steps to be taken is set to 10 and 25 for small and large amplitude load steps, respectively.

\section{Validation of FE Analysis}

This section describes the calibration of the FE modeling for different specimens, including two steel plate fuses (DSD5 and PSD-5) from the experimentally tested specimens by Lee et al. [18] and three single-link specimens each with different governing limit states [19]. Fig. 5 illustrates the lateral load versus lateral deformation of specimen models DSD-5 and PSD5 in comparison with the experimental hysteretic curves. As observed in Fig. 5, the numerical results obtained from the FE simulations are in good agreement with the experimental test results. The predicted peak strength error using the FE model is $1.14 \%$ and $3.50 \%$ for specimen models PSD-5 and DSD-5, respectively. The error percentage is obtained from $\left(P_{\max }^{F E}-P_{\max }^{T e s t}\right) / P_{\max }^{T e s t} \times 100$, where $P_{\max }^{F E}$ and $P_{\max }^{T e s t}$ are the peak strength from the FE analysis and the experimental test, respectively.
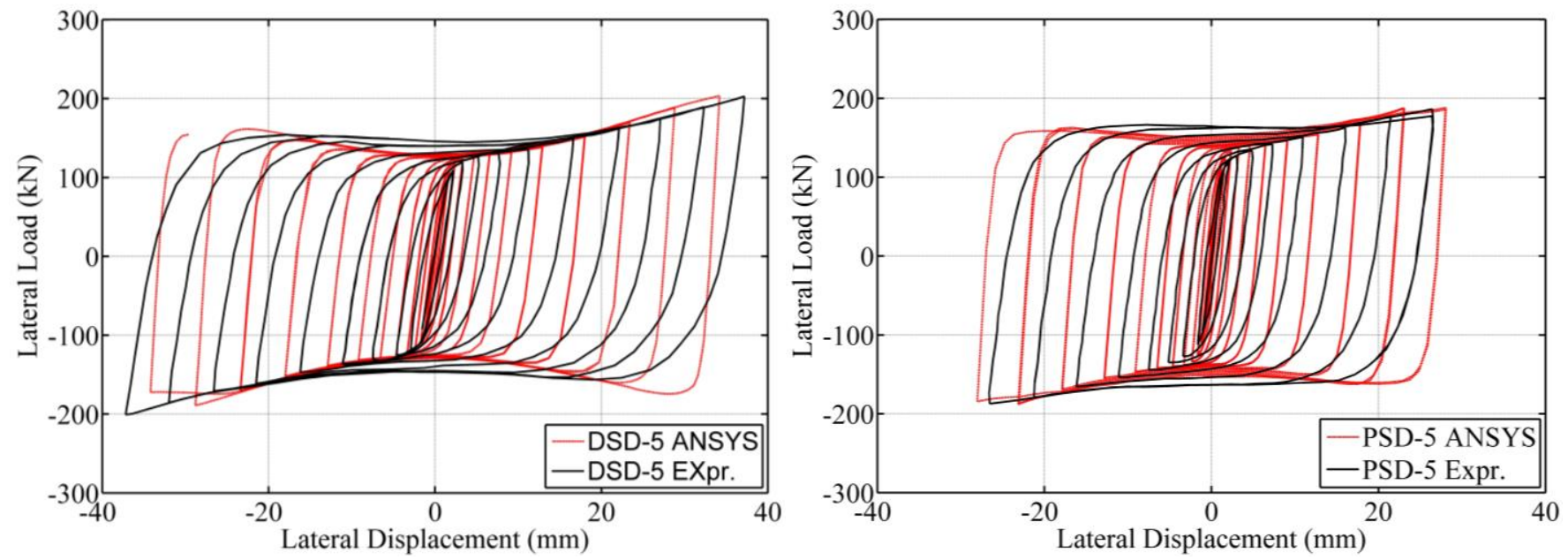

Fig. 5: Cyclic load-displacement response of specimens DSD-5 and PSD-5: FE simulation and experimental results comparison. 
The accuracy of the FE analysis in predicting the limit states of butterfly-shaped fuses is further verified against three specimen models analyzed by Farzampour and Eatherton [19]. The dimensional details of each specimen models are listed in Table 1. These models have only one link of the butterfly-shaped and slit fuses to reduce computational cost. As the sensitivity study is also considering one link of the fuse, the FE model is validated with the reference numerical results. It is worth mentioning that the reference study is also based on validations against experiment [11]. The lateral load-displacement plots of these specimens are compared and illustrated in Fig. 6.

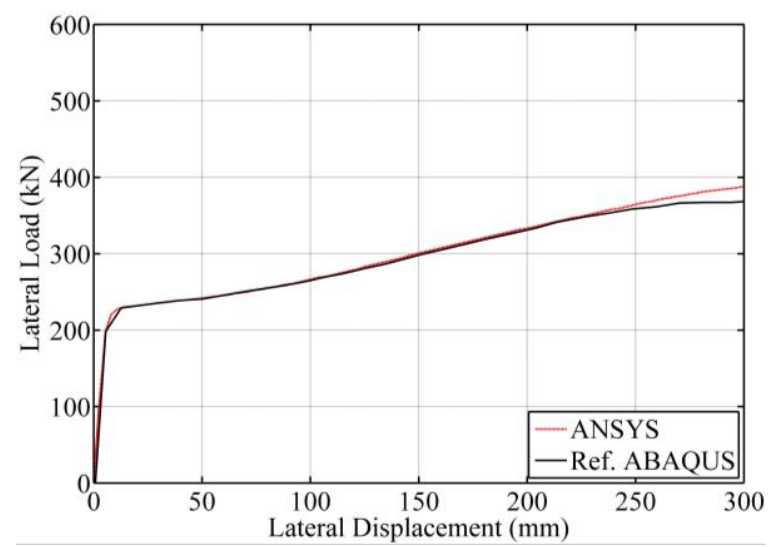

(a)

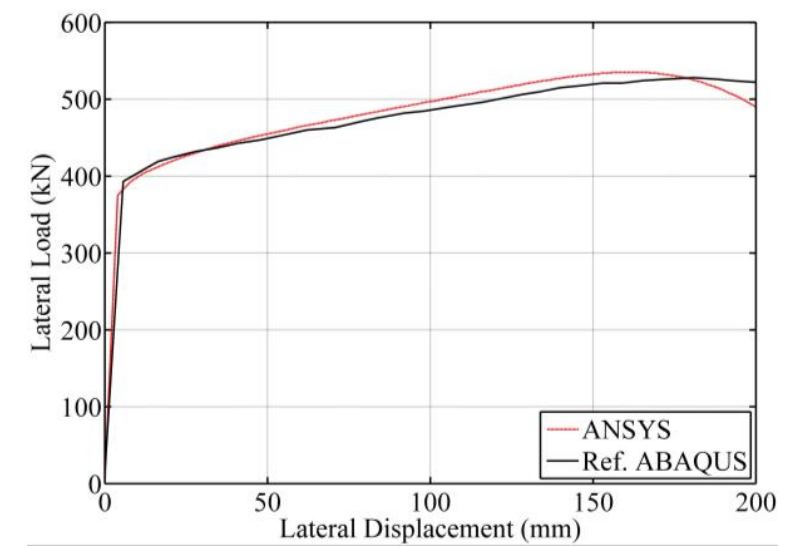

(b)

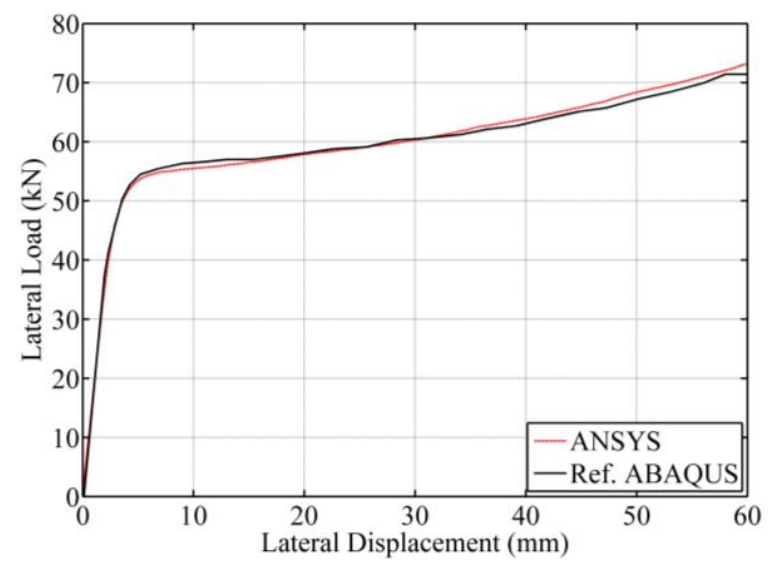

(c)

Fig. 6: Validation of the FE modeling: (a): flexural yielding, (b): shear yielding, (c): lateral torsional buckling.

\section{Sensitivity Analyses}

A sensitivity study of the cyclic load-displacement response of steel plate fuses is carried out to determine the effects of different design parameters on different response variables using statistical design of experiment method and the calibrated FE models. Seven different factors that are potentially influential on the cyclic response variables of steel plate fuses are chosen. The factors include both geometry-related factors (the fuse length, mid-width, end-width, thickness, and band zone length) and material-related factors (the steel yield strength and modulus of elasticity). Two levels that represent the maximum and minimum values are considered for each input factor. Table 2 lists these input parameters along with their levels. The ranges of each factor are chosen to be broad and practical based on previous experimental studies (e.g., [11], [18]). 
Table 2: Design factors and ranges considered for the sensitivity study.

\begin{tabular}{|c|c|c|c|c|}
\hline Factors & Symbol & Low level (-) & High level (+) & Units \\
\hline Length & $L$ & 180 & 500 & $\mathrm{~mm}$ \\
\hline Mid-width & $a$ & 15 & 36 & $\mathrm{~mm}$ \\
\hline End-width & $b$ & 36 & 200 & $\mathrm{~mm}$ \\
\hline Thickness & $t$ & 5 & 40 & $\mathrm{~mm}$ \\
\hline Steel yield strength & $F_{y}$ & 245 & 340 & $\mathrm{MPa}$ \\
\hline Modulus of elasticity & $E$ & 185000 & 212000 & $\mathrm{MPa}$ \\
\hline Band zone length & $c$ & 5 & 75 & $\mathrm{~mm}$ \\
\hline
\end{tabular}

\subsection{Factor Combinations and Response Characteristics}

The sensitivity study is conducted using Design-Expert software [21]. One-fourth fractional factorial design with 2levels having a resolution of four is treated for the analysis. The design requires 32 runs of different factor combinations that are generated by Design-Expert software. For each factor combination, a FE model is generated and analyzed under cyclic loading. For further details, the reader is referred to reference [22].

The cyclic load-displacement response of each FE model is recorded. As the output of each simulation, six different response characteristics are computed. These response values include: (1) the initial stiffness, $K$; (2) yield strength, $P_{y}$; (3) ultimate stiffness, $K^{\prime}$; (4) effective damping, $\beta_{e f f} ;(5)$ peak strength, $P$; and (6) ductility, $\mu$. Further details are presented in reference [22].

\subsection{Sensitivity Study Results}

The effects of input factors along with the presence of any active interaction between the design parameters on the response characteristics are evaluated. The percentage contributions of influential design factors and their interaction for each response variable are presented in Table 3. The positive sign is the indicator of a direct (or increasing) effect for the corresponding factor or interaction. For example, Table 3 shows that the initial stiffness is increased when factor $b$ is increased from its low level to high level. Further details is available in reference [22].

Table 3: Percentage contribution of design factors and interactions on each response characteristic.

\begin{tabular}{|c|c|c|c|c|c|c|c|c|c|c|c|}
\hline \multicolumn{12}{|c|}{ Response variable } \\
\hline \multicolumn{2}{|c|}{ Initial Stiffness } & \multicolumn{2}{|c|}{ Yield Strength } & \multicolumn{2}{|c|}{ Ultimate Stiffness } & \multicolumn{2}{|c|}{ Effective Damping } & \multicolumn{2}{|c|}{ Peak Strength } & \multicolumn{2}{|c|}{ Ductility } \\
\hline Factor & $\begin{array}{c}\text { Contribution } \\
\%\end{array}$ & Factor & $\begin{array}{c}\text { Contribution } \\
\%\end{array}$ & Factor & $\begin{array}{c}\text { Contribution } \\
\%\end{array}$ & Factor & $\begin{array}{c}\text { Contribution } \\
\%\end{array}$ & Factor & $\begin{array}{c}\text { Contribution } \\
\%\end{array}$ & Factor & $\begin{array}{c}\text { Contribution } \\
\%\end{array}$ \\
\hline$b$ & 22 & $b$ & 29 & $b$ & 24 & $t$ & 29 & $t$ & 43 & $t$ & 30 \\
\hline$t$ & 15 & $t$ & 29 & $t$ & 20 & $b$ & \begin{tabular}{|l|l|} 
& -12 \\
\end{tabular} & $b$ & 23 & $L$ & -26 \\
\hline$L$ & -15 & $b t$ & 18 & $L t$ & -8 & $b t$ & -11 & $b t$ & 16 & $c$ & -9 \\
\hline$L b$ & -12 & $a b$ & 5 & $b t$ & 6 & $a t$ & 7 & at & 3 & $L t$ & -5 \\
\hline$L t$ & -9 & $L$ & -2 & c & 5 & $F_{y}$ & 5 & $L$ & -3 & $a b$ & -3 \\
\hline$a E$ & -7 & & & $L C$ & -4 & $t F_{y}$ & 5 & $L t$ & -2 & $L c$ & 3 \\
\hline & & & & $a E$ & -3 & $b F_{y}$ & -4 & & & $L E$ & -3 \\
\hline
\end{tabular}




\section{Conclusion}

This paper summarizes a study on the FE simulation and sensitivity analysis of energy dissipating steel plate fuses. Details regarding the development of FE modeling, boundary conditions, element type, material and meshing properties, loading history and analysis are discussed. Next, a sensitivity analysis is performed to determine the effect of different factors on the cyclic response of steel plate shear links. The following conclusions are summarized below:

- Accurate FE results are obtained when using SHELL181 and NLISO material model. A meshing density having an element size of $3.5 \mathrm{~mm}$ is observed to give satisfactory level of accuracy for the load-deformation response of the fuses.

- The end-width and thickness of steel plate shear links influence all the cyclic response characteristics whereas the length and mid-width are influential on some of the response variables - given the ranges considered for the design factors in this study.

- The cyclic response is not greatly sensitive to the variation in the modulus of elasticity, steel yield strength, and the band zone length.

- The initial stiffness of steel plate fuses is mainly affected by the end-width, thickness, length, and their interactions with a combined percentage contribution of $92 \%$.

- The yield strength of a steel plate fuse is mainly controlled by the fuse link end-width, thickness, mid-width, and length, - accounting for approximately $87 \%$ of the total variability in the response.

- The ultimate stiffness of a steel plate fuse is mostly sensitive to end-width, thickness, and length. These parameters with their interactions account for about $65 \%$ of the total response variability.

- The important factors that significantly impact the effective damping response are the thickness and the end-width having a combined contribution of more than $50 \%$.

- The most significant parameters and interactions influencing the load capacity of steel plate fuses are the thickness, end-width, mid-width, and length. Overall, the percentage contribution of these parameters and their interactions account for $94 \%$ of the total variability in the response.

- The factors that mostly influence the ductility of steel plate fuses are the thickness, length, end-width, and the band zone length. The percentage contribution of these factors and their interactions is found to be about $85 \%$ of the total variability in the ductility response.

\section{Acknowledgements}

The financial support from the Natural Sciences and Engineering Research Council of Canada (NSERC) through Discovery Grant and the Ryerson University Faculty of Engineering and Architectural Science is gratefully acknowledged.

\section{References}

[1] G. W. Housner, L. A. Bergman, T. K. Caughey, A. G. Chassiakos, R. O. Claus, S. F. Masri, R. E. Skelton, T. T. Soong, B. F. Spencer, and J. T.P. Yao, "Structural control: Past, present, and future," J. Eng. Mech., vol. 123, no. 8, pp. 897-972, 1997.

[2] M. A. Lackner and M. A. Rotea, "Passive structural control of offshore wind turbines," Wind Energy, vol. 14, no. 3, pp. 373-388, 2011.

[3] J. E. Mart1'nez-Rueda, "On the evolution of energy dissipation devices for seismic design," Earthq. Spectra, vol. 18, no. 2, pp. 309-346, 2002.

[4] Y. Kurokawa, M. Sakamoto, T. Yamada, H. Kurino, and A. Kunisue, "Seismic design of a tall building with energy dissipation damper for the attenuation of torsional vibration," Struct. Des. Tall Build., no. 7, pp. 21-32, 1998.

[5] G. Deierlein, H. Krawinkler, X. Ma, M. Eatherton, J. Hajjar, T. Takeuchi, K. Kasai, and M. Midorikawa, "Earthquake resilient steel braced frames with controlled rocking and energy dissipating fuses," Steel Constr., vol. 4, no. 3, pp. 171-175, Aug. 2011.

[6] S. Moradi, H. V. Burton, and I. Kumar, "Parameterized fragility functions for controlled rocking steel braced frames," 
Eng. Struct., vol. 176, pp. 254-264, 2018.

[7] J. M. Kelly, R. I. Skinner, and A. J. Heine, "Mechanisms of energy absorption in special devices for use in earthquake resistant structures," Bull. New Zeal. Soc. Earthq. Eng., vol. 5, no. 3, pp. 63-88, 1972.

[8] C. H. Lee, S. H. Lho, D. H. Kim, J. Oh, and Y. K. Ju, "Hourglass-shaped strip damper subjected to monotonic and cyclic loadings," Eng. Struct., vol. 119, pp. 122-134, 2016.

[9] I. H. Mualla and B. Belev, "Performance of steel frames with a new friction damper device under earthquake excitation," Eng. Struct., vol. 24, pp. 365-371, 2002.

[10] F. Bartera and R. Giacchetti, "Steel dissipating braces for upgrading existing building frames," J. Constr. Steel Res., vol. 60, no. 3-5, pp. 751-769, 2004.

[11] X. Ma, E. Borchers, A. Pena, H. Krawinkler, S. Billington, and G. G. Deierlein, "Design and behavior of steel shear plates with openings as energy-dissipating fuses," Intern. Report, John A. Blume Earthq. Eng. Center, Stanford Univ., no. $17,2011$.

[12] R. W. K. Chan and F. Albermani, "Experimental study of steel slit damper for passive energy dissipation," Eng. Struct., vol. 30, pp. 1058-1066, 2008.

[13] K. Ghabraie, R. Chan, X. Huang, and Y. M. Xie, "Shape optimization of metallic yielding devices for passive mitigation of seismic energy," Eng. Struct., vol. 32, no. 8, pp. 2258-2267, 2010.

[14] K. Deng, P. Pan, J. Sun, J. Liu, and Y. Xue, "Shape optimization design of steel shear panel dampers," J. Constr. Steel Res., vol. 99, pp. 187-193, 2014.

[15] ANSYS, “ANSYS Mechanical APDL.” ANSYS, Inc., Canonsburg, PA, 2019.

[16] A. Farzampour and M. R. Eatherton, "Yielding and lateral torsional buckling limit states for butterfly-shaped shear links," Eng. Struct., vol. 180, no. November 2018, pp. 442-451, 2019.

[17] G. Li and H. N. Li, "Experimental study and application in steel structure of 'dual functions' metallic damper," Adv. Steel Constr., 2013.

[18] C. H. Lee, Y. K. Ju, J. K. Min, S. H. Lho, and S. D. Kim, "Non-uniform steel strip dampers subjected to cyclic loadings," Eng. Struct., 2015.

[19] A. Farzampour and M. Eatherton, "Investigating limit states for butterfly-shaped and straight shear links," 2018, pp. $1-12$.

[20] V. Budaházy and L. Dunai, "Parameter-refreshed Chaboche model for mild steel cyclic plasticity behaviour," Period. Polytech. Civ. Eng., vol. 57, no. 2, pp. 139-155, 2013.

[21] DX10.0.7, "Design-Expert ${ }^{\circledR}$ Software Version 9.” Stat-Ease, Inc., Minneapolis, M.N, 2017.

[22] A. S. Mahmood Shah and S. Moradi, "Cyclic response sensitivity of energy dissipating steel plate fuses," Structures, vol. 23, no. December 2019, pp. 799-811, 2020. 